\title{
Expression of nm23-H1 and COX-2 in thyroid papillary carcinoma and microcarcinoma
}

\author{
MARIJA MILKOVIC PERISA ${ }^{1,4}$, BOZENA SARCEVIC $^{1}$, KORALJKA GALL TROSELJ ${ }^{2}$, \\ KRESIMIR GRSIC ${ }^{3}$, SANDA SITIC ${ }^{1}$ and SVEN SEIWERTH ${ }^{4}$ \\ ${ }^{1}$ Department of Pathology, School of Medicine, University Hospital for Tumours, \\ Sisters of Charity Clinical Hospital Center, Zagreb 10000; ${ }^{2}$ Laboratory for Epigenomics, \\ Division of Molecular Medicine, Rudjer Bošković Institute; ${ }^{3}$ Division of Head and Neck Surgery, \\ Department of Surgical Oncology, University Hospital for Tumours, Sisters of Charity Clinical Hospital \\ Center; ${ }^{4}$ Department of Pathology, School of Medicine, University of Zagreb, Zagreb 10000, Croatia
}

Received August 14, 2016; Accepted January 6, 2017

DOI: $10.3892 / \mathrm{ol} .2017 .5876$

\begin{abstract}
The expression of non-metastatic expressed/non-metastatic 23 nucleoside diphosphate kinase 1 (nm23-H1) and cyclooxygenase 2 (COX-2) proteins in thyroid carcinoma have been analysed in a number of previous studies, but this requires further study. The current study focused on the expression levels of nm23-H1 and COX-2 in 130 human thyroid papillary carcinoma (PTC) tissues. Of the 130 PTC tissues, 55 were classified as microcarcinoma and may provide information on the development of the specific characteristics of this tumour type. Routine histopathological examination and immunohistochemical detection of nm23-H1 and COX-2 expression was performed on 130 PTC tissues from patients treated in the Clinical Hospital for Tumours (Zagreb, Croatia) between January 2000 and December 2007. The stain intensity of nm23-H1 and COX-2 proteins was compared with the characteristics of the patients and the tumour. The highest overall expression rate of $\mathrm{nm} 23-\mathrm{H} 1$ and COX-2 was 90 and $67.6 \%$, respectively, and the joint expression of these proteins was statistically significant. The median expression level of nm23-H1 was significantly increased in the classical and
\end{abstract}

Correspondence to: Dr Marija Milkovic Perisa, Department of Pathology, School of Medicine, University Hospital for Tumours, Sisters of Charity Clinical Hospital Center, Ilica 197, Zagreb 10000, Croatia

E-mail:mmperisa@gmail.com

Dr Kresimir Grsic, Division of Head and Neck Surgery, Department of Surgical Oncology, University Hospital for Tumours, Sisters of Charity Clinical Hospital Center, Ilica 197, Zagreb 10000, Croatia E-mail: kresimir.grsic@yahoo.com

Key words: thyroid papillary carcinoma, thyroid papillary microcarcinoma, immunohistochemistry, cyclooxygenase 2, non-metastatic expressed/non-metastatic 23 nucleoside diphosphate kinase 1, metastases follicular histological group of the PTC tissues compared with tissues from other histological groups. The median expression level of COX-2 was significantly increased in the follicular histological group, and reduced in the diffuse-sclerosing group of PTC tissues. All the metastatic microcarcinoma tissues had increased expression levels of the two proteins in comparison with microcarcinoma tissues without lymph node metastases; however, this variation was only statistically significant for COX-2 expression levels. Therefore the results of the current study indicate that COX-2 protein levels may be able to differentiate which thyroid papillary microcarcinoma tumours possess metastatic potential.

\section{Introduction}

Papillary thyroid carcinoma (PTC) is the most prevalent type of malignancy of the thyroid gland and the endocrine system (1). PTC incidence is increased in the female population during the reproductive phase of development (1). Although PTC typically has a good prognosis, there is a group of patients $(<10 \%)$ that present with tumours exhibiting aggressive characteristics (1). Therefore, numerous previous studies have investigated the parameters that have the potential to be independent prognostic factors of PTC (1-5). In the World Health Organisation Classification of Tumours of Endocrine Organs, the prognosis of PTC depends on whether a patient may be in the 'risk group', which is defined by the following parameters: a) The patient being $<45$ years; b) the size of the tumour is $>4$ $\mathrm{cm}$; c) the presence of extrathyroidal extension; d) the effectiveness of the surgery; e) the presence of distant metastases (1). The tall cell and columnar cell histological subtypes of PTC have a poor prognosis compared with classical PTC (1). The diffuse sclerosing variant of PTC may present with prominent regional lymph node and lung metastases in $<25 \%$ of patients compared with the classical type of PTC, which also may present with regional lymph node metastases in $25 \%$ of patients, but not lung metastases (1). Toniato et al (2) examined various factors that potentially influenced tumour recurrence and the survival rate in a group of 950 patients with PTC, with an average follow-up time of 7.8 years. This previous study 
hypothesised that age at the time of diagnosis ( $>45$ years), an advanced disease stage (T4; distant metastases; stage IV), the extent of thyroid surgery (subtotal thyroid surgery) and the lack of administration of radioiodine 131-I therapy were effective and independent prognostic factors for the recurrence of disease (2). Spriano et al (3) studied the pattern of regional lymph node metastases and potential prognostic factors in differentiated thyroid carcinoma. This previous study included 72 patients with PTC with regional lymph node metastases, of which $18 \%$ developed recurrence after 6 years of disease-free survival (3). The results from this previous study identified that nodal metastases have a significant prognostic impact, particularly nodal extracapsular spread, which was established to be a potential predictive factor for distant metastasis and the regional recurrence of PTC (3). Another previous study performed on 6,015 patients with PTC demonstrated that a tumour size $>4 \mathrm{~cm}$, the presence of large extrathyroid extension, an age of $\geq 55$, being of the male gender and the presence of lymph node metastasis in the lateral compartment are independent prognostic factors for reduced tumour-specific survival (4). Jung et al (5) investigated the clinical features and prognostic factors associated with survival in patients with poorly differentiated thyroid carcinoma and with aggressive variants of PTC, including the tall cell, columnar cell, solid and diffuse sclerosing variants of PTC. The results identified that an age of $>45$ years, a tumour size $>4 \mathrm{~cm}$, extrathyroidal invasion, cervical lymph node metastases, distant metastasis, the absence of high-dose radioactive iodine therapy and the tumour-node-metastasis (TNM) classification of malignant tumour stages II, III and IV were significantly associated with poor prognostic factors for survival using univariate analysis (5).

The variant of PTC identified as 'papillary microcarcinoma' is defined as a tumour that is $<1 \mathrm{~cm}$ in diameter (1) and these tumours are frequently identified incidentally. Within this type of tumour there is a subgroup that presents with cervical lymph node metastasis at the time of diagnosis (1). These tumour tissues typically have specific immunohistochemical features compared with incidentally identified microcarcinoma, which include a loss of p27 and upregulation of cyclin D1 expression levels reflecting a variation in biological characteristics and indicating distinct clinical behaviour (1).

The non-metastatic expressed/non-metastatic 23 (nm23) gene has been established to be included in a group of tumour suppressor genes (6). The non-metastatic expressed/non-metastatic 23 nucleoside diphosphate kinase 1 (nm23-H1) was the first identified member of the nm23 gene family and its role in tumour suppression has been examined in numerous types of malignant tumour (7-10). However, the results from previous studies have not elucidated its role in thyroid carcinogenesis (11-15). Although a number of previous studies have indicated that high levels of nm23-H1 expression in the advanced stages of papillary and follicular thyroid carcinoma are indicative of its role in proliferation $(11,12)$, there are previous studies that have presented contrasting results (13-15). Notably, to the best of our knowledge there are no studies demonstrating a statistically significant correlation between nm23-H1 expression levels and the biological characteristics of PTC, including the presence of lymph node metastases (13-17).
Prostaglandin-endoperoxide synthase 1 and 2 [also termed cyclooxygenase (COX)-1 and COX-2] are key enzymes in the synthesis of prostaglandins from arachidonic acid (18). The COX-1 enzyme is encoded by the gene located on chromosome 9 at q33.2, and it is constitutively expressed in almost all tissues $(19,20)$. The COX-2 enzyme is encoded by the gene located on chromosome 1 at q31.1 and is an inducible isozyme primarily expressed at sites of inflammation (21). The increased expression of COX-2 has been detected in numerous types of carcinoma $(22,23)$. A number of studies demonstrated that COX-2 expression is increased in the elderly (without papillary cancer) but decreased in follicular variant of papillary cancer. By contrast, other studies have detected increased expression of COX-2 in papillary cancer tissues compared with normal tissues without significant statistical differences. However, the sample sizes in these studies were small. COX-2 expression is decreased in patients with papillary cancer, large tumor masses and advanced stage (24-33). A number of previous studies have demonstrated that COX-2 expression levels were significantly increased in malignant nodular changes of the thyroid compared with benign nodular changes of the thyroid (24-26). The results of this previous study indicated that COX-2 may not be an effective diagnostic marker of thyroid malignancy (28). Concordant with other previous studies, the upregulation of $\mathrm{COX}-2$ expression may significantly contribute to the progression of PTC, particularly in early stages of the disease (28-31). Previous studies have also established that the expression levels of COX-2 in PTC and inflammatory thyroid disease may provide a bridge for an association between carcinogenesis and inflammation in the thyroid gland $(28,32,33)$. Due to the contradictory results in previous studies, the role of COX-2 in papillary cancer remains to be elucidated.

Epstein-Barr virus (EBV)-infected cells have been established to be an optimal model for investigating the association between nm23-H1 and COX-2 (34). A previous study using these cells suggested that COX-2 expression was promoted by the induction of $n m 23-\mathrm{H} 1$ expression via the nuclear factor- $\kappa \mathrm{B}$ $(\mathrm{NF}-\kappa \mathrm{B})$ signalling pathway (34). Therefore, the current study investigated the role of the expression levels of nm23-H1 and COX-2 proteins in 130 samples of PTC, including 75 PTC cases and 55 microcarcinoma tumours.

\section{Materials and methods}

Patient information and tissue samples. The archived tissue samples from patients with PTC were fixed in $10 \%$ neutral-buffered formalin, embedded in paraffin, sectioned, stained with haematoxylin and eosin and archived at the Department of Pathology (University Hospital for Tumours, Zagreb, Croatia) as described below. The tissues were from 130 patients who underwent partial or total thyroidectomy with paratracheal lymph node dissection at the Department of Head and Neck Surgery at the University Hospital for Tumours between January 2000 and December 2007. These samples were subclassified using the World Health Organisation classification (1) were classified as follows: 67 papillary; 32 follicular; 13 sclerosing; 10 oxyphilic histological subtype; 8 classified as 'other' (1 macrofollicular, 1 insular, 1 clear-cell, 1 tall-cell and 4 tumours with combined classification types, 
including 2 sclerosing-oxyphilic, 1 follicular-insular and 1 follicular-oxyphilic) (1).

All samples were subsequently analysed for the following four parameters: a) The presence of lymphocytic inflammatory infiltrate; b) the presence of intraglandular dissemination; c) any additional benign changes in the thyroid gland tissue; d) the presence of metastases in lymph nodes.

Tissue blocks were cut into $4 \mu \mathrm{m}$ sections and were dried onto slides for $12-24 \mathrm{~h}$ at $>60^{\circ} \mathrm{C}$. Tissue sections were deparaffinised in xylene and rehydrated using graded alcohol and deionised $\mathrm{H}_{2} \mathrm{O}$. The sections were heated in a microwave in a $0.3 \%$ citrate buffer, $\mathrm{pH} 6.0$ (cat. no. S1699; Target Retrieval Solution; DAKO; Agilent Technologies, Inc., Santa Clara, CA, USA) 4 times for 5 min each and washed with PBS twice for $5 \mathrm{~min}$. Slides were incubated with mouse monoclonal COX-2 (dilution, 1:100; cat. no. sc-58344; Santa Cruz Biotechnology, Inc., Dallas, TX, USA) and mouse monoclonal nm23-H1 (dilution, 1:200; cat. no. sc-56928; Santa Cruz Biotechnology, Inc.) antibodies for $30 \mathrm{~min}$ at room temperature. Immunohistochemical staining was performed with a Dako Autostainer using the EnVision+ horseradish peroxidase 3,3'-Diaminobenzidine system (cat. no. K8000 Envision Flex; Dako; Agilent Technologies, Inc.), which includes secondary antibody (30 min at room temperature) according to the manufacturer's protocol. Subsequently, the sections were washed in $\mathrm{H}_{2} \mathrm{O}$ for $10 \mathrm{~min}$, counterstained with Meyer's haematoxylin for 15-60 sec and washed. The images were captured with a ZEISS Axiostar plus microscope (Zeiss AG, Oberkochen, Germany). Paraffin blocks of colorectal cancer established as being positive for COX-2 expression and ductal invasive breast cancer established as being positive for $\mathrm{nm} 23-\mathrm{H} 1$ expression were used as a positive control. The archived tissue samples from patients with colorectal and breast cancer were fixed in $10 \%$ neutral-buffered formalin, embedded in paraffin, sectioned, stained with haematoxylin and eosin and archived at Department of Pathology (University Hospital for Tumours, Zagreb, Croatia) (35-39).

Immunoreactivity scores (IRS) were obtained by multiplying the scores (MS, multiplied score) of staining intensity and the size of immunoreactive area. The intensity of stain was scored as follows: 0 , absent; 1 , mild; 2 , moderate; 3 , strong. The immunoreactive area was scored as follows: 0, negative; $1,<10 \% ; 2,10-50 \% ; 3,>50 \%$ of cells stained. The IRS scores were collated as follows: 0 , MS $0 ; 1$, MS $1-3 ; 2$, MS 4 or $6 ; 3$, MS 9.

Statistical analysis. Quantitative variables were presented as median values and corresponding interquartile ranges and categorical variables were presented as absolute frequencies and corresponding percentages. The variation in IRS values for nm23-H1 and COX-2 expression levels and clinical (age, gender, tumour size and presence of lymph node metastases) and histological variables (histological subtype of tumour, lymphocytic infiltration and presence of additional benign thyroid diseases) was assessed with the $\chi^{2}$ test. The Kruskal-Wallis test was used to determine statistically significant differences between the median age, tumour size and nm23-H1 and COX-2 IRS values. SPSS Statistics for Windows version 21 (IBM SPSS, Armonk, NY, USA) was used for all statistical tests. $\mathrm{P}<0.05$ was considered to indicate a statistically significant difference.

\section{Results}

The present study examined samples from 130 patients with PTC with the following data: Age, gender, localization and size of the tumour, histological subtype, the presence of lymphocytic infiltration and additional benign changes in the thyroid gland, intraglandular spread of the tumour and the presence of lymph node metastases.

In the current study, PTCs occurred in female patients (107/130) that were aged between 20 and 80 years (median, $49.5)$ and primarily in the right lobe (74/130). The size of the tumour varied from $0.3-6.5 \mathrm{~cm}$ (median, $1.2 \mathrm{~cm}$ ) and 55 of the tumours were $\leq 1 \mathrm{~cm}$ in diameter. From examining the tumour morphology the following classifications were made: 67 papillary; 32 follicular; 13 diffuse sclerosing; 10 oxyphilic subtype; 8 classified as 'other'. The latter group consisted of 1 macrofollicular, 1 insular, 1 clear-cell, 1 tall-cell; 4 of combination subtypes, including 2 sclerosing-oxyphilic, 1 follicular-insular and 1 follicular-sclerosing PTC tumour. Lymphocytic infiltration was present in 39/130 of tumour samples. Intraglandular dissemination was identified in 37 samples and lymph node metastases were present in 27 patients. Additional benign changes in the surrounding tissue of the thyroid gland, including follicular adenoma, lymphocytic thyroiditis, Hashimoto thyroiditis and goitre were present in 65 patients. The most frequent type of benign change was thyroiditis, which included Hashimoto and lymphocytic thyroiditis and was present in 33 patients.

Immunohistochemical results (Table I) indicated that there was moderate-strong to strong cytoplasmic staining for nm23-H1 and COX-2 (Figs. 1 and 2) in 118/130 and 88/130 of the samples, respectively. COX-2 and nm23-H1 were coexpressed in all but two tumours $(\mathrm{P}<0.001$; Table II).

In the present study, the expression levels of nm23-H1 and COX-2 were not associated with the patient's age, gender, intraglandular dissemination of the tumour, tumour diameter and the presence of metastatic regional lymph nodes. However, statistically significant differences were identified between histological subtypes. The nm23-H1 median expression levels were significantly increased in the classical and follicular histological subtype compared with other histological subtypes $(\mathrm{P}=0.038)$. The $\mathrm{COX}-2$ median expression levels were significantly increased in patients with follicular histological subtype and decreased in the diffuse-sclerosing subtype compared with patients with follicular, papillary, oxyphilic and sclerosing papillary cancer ( $\mathrm{P}=0.006$; Table III). The subgroup 'others' was not included in this analysis as it represents a number of distinct histological subtypes. The presence of lymphocytic inflammatory infiltrate in the tumour was significantly associated with thyroiditis in the surrounding non-tumorous tissue $(\mathrm{P}<0.001$; Table IV), but this did not associate with the expression levels of nm23-H1 and COX-2 in the tumour tissues $(\mathrm{P}=0.677$ and $\mathrm{P}=0.649$, respectively).

No single tumour was negative for nm23-H1 and COX-2. However, a total of nine tumours were negative for one of the proteins ( $\mathrm{nm} 23-\mathrm{H} 1, \mathrm{n}=2 ; \mathrm{COX}-2, \mathrm{n}=7)$. The characteristics of these tumours are presented in Table V. From the nine samples, it may be hypothesized that the regulation of COX-2 expression is complex and that, in the present 
Table I. Distribution of patients with papillary carcinoma.

\begin{tabular}{|c|c|c|c|c|c|}
\hline \multirow[b]{2}{*}{ Characteristics } & \multirow[b]{2}{*}{ Total } & \multicolumn{2}{|c|}{$\mathrm{nm} 23-\mathrm{H} 1$} & \multicolumn{2}{|c|}{ COX -2} \\
\hline & & Score 0,1 & Score 2,3 & Score 0,1 & Score 2,3 \\
\hline \multicolumn{6}{|l|}{ Age, years } \\
\hline$\leq 45$ & 49 & 4 & 45 & 12 & 37 \\
\hline$>45$ & 81 & 8 & 73 & 30 & 51 \\
\hline \multicolumn{6}{|l|}{ Gender } \\
\hline Male & 23 & 2 & 21 & 8 & 15 \\
\hline Female & 107 & 10 & 97 & 34 & 73 \\
\hline \multicolumn{6}{|l|}{ Localization } \\
\hline Right lobe & 74 & 7 & 67 & 21 & 53 \\
\hline Left lobe & 47 & 5 & 42 & 19 & 28 \\
\hline Isthmus & 9 & 0 & 9 & 2 & 7 \\
\hline \multicolumn{6}{|l|}{ Tumour size, $\mathrm{cm}$} \\
\hline$\leq 1$ & 55 & 5 & 50 & 19 & 36 \\
\hline$>1$ & 75 & 7 & 68 & 23 & 52 \\
\hline \multicolumn{6}{|c|}{ Histological type } \\
\hline Classical & 67 & 6 & 61 & 21 & 46 \\
\hline Follicular & 32 & 1 & 31 & 6 & 26 \\
\hline Sclerosing & 13 & 3 & 10 & 8 & 5 \\
\hline Oxyphilic & 10 & 1 & 9 & 4 & 6 \\
\hline Other & 8 & 1 & 7 & 3 & 5 \\
\hline \multicolumn{6}{|c|}{ Lymphocytic infiltration } \\
\hline Present & 39 & 5 & 34 & 13 & 26 \\
\hline Absent & 91 & 7 & 84 & 29 & 62 \\
\hline \multicolumn{6}{|l|}{ Benign changes } \\
\hline Present & 65 & 5 & 60 & 25 & 40 \\
\hline Absent & 65 & 7 & 58 & 17 & 48 \\
\hline \multicolumn{6}{|c|}{ Intraglandular spread } \\
\hline Present & 37 & 4 & 33 & 11 & 26 \\
\hline Absent & 93 & 8 & 85 & 31 & 62 \\
\hline \multicolumn{6}{|c|}{ Lymph node metastasis } \\
\hline Present & 27 & 1 & 26 & 7 & 20 \\
\hline Absent & 103 & 11 & 92 & 35 & 68 \\
\hline
\end{tabular}

nm23-H1, non-metastatic expressed/non-metastatic 23 nucleoside diphosphate kinase 1; COX-2, cyclooxygenase 2.

study, a direct link between nm23-H1 and COX-2 was not able to be elucidated. It is also of note that the tumours from patients \#83, \#87 and \#115 exhibited the highest score for nm23-H1 expression levels, but were negative for COX-2 expression.

The current study divided the tumour samples into two groups depending on the tumour size $(n=55$, papillary microcarcinoma; $n=75$, papillary carcinoma) and no statistically significant difference was found in the expression levels of nm23-H1 and COX-2 between the groups $(\mathrm{P}=0.924$ and $\mathrm{P}=0.432$ ). The group of tumours with a diameter of $\leq 1 \mathrm{~cm}$ (microcarcinoma) were divided into two distinct groups, which was due to the presence or absence of lymph node metastases ( $n=9$ and $n=46$, respectively). The results of the current study indicated that papillary microcarcinoma with lymph node metastases exhibited increased expression levels of nm23-H1 and COX-2 (Tables VI and VII), but a statistically significant difference was only established for the levels of COX-2 expression $(\mathrm{P}=0.017)$.

\section{Discussion}

COX-2 is an enzyme that is expressed at sites of inflammation and in numerous types of carcinoma, and this may be associated with their aggressive characteristics $(22,23)$. COX-2 is also expressed in benign and malignant thyroid tumours, particularly in papillary carcinoma; however, the underlying mechanistic role and potential association 
Table II. Coexpression of nm23-H1 and COX-2.

\begin{tabular}{lcccc}
\hline & \multicolumn{3}{c}{$\mathrm{nm} 23-\mathrm{H} 1$ score } \\
\cline { 3 - 4 } & & 1,2 & 3,4 & Total \\
\hline COX-2 score & $\mathrm{n}$ & 11 & 31 & \\
1,2 & $\%$ & 26.2 & 73.8 & 100 \\
3,4 & $\mathrm{n}$ & 1 & 87 & 88 \\
& $\%$ & 1.1 & 98.9 & 100 \\
Total & & & & \\
& $\mathrm{n}$ & 12 & 118 & 130 \\
& $\%$ & 9.2 & 90.8 & 100 \\
\hline
\end{tabular}

$\chi^{2}$ test $=21.300$, degrees of freedom $=1, \quad \mathrm{P}<0.001 . \mathrm{nm} 23-\mathrm{H} 1$, non-metastatic expressed/non-metastatic 23 nucleoside diphosphate kinase 1 ; COX-2, cyclooxygenase 2 ; n, number of samples.

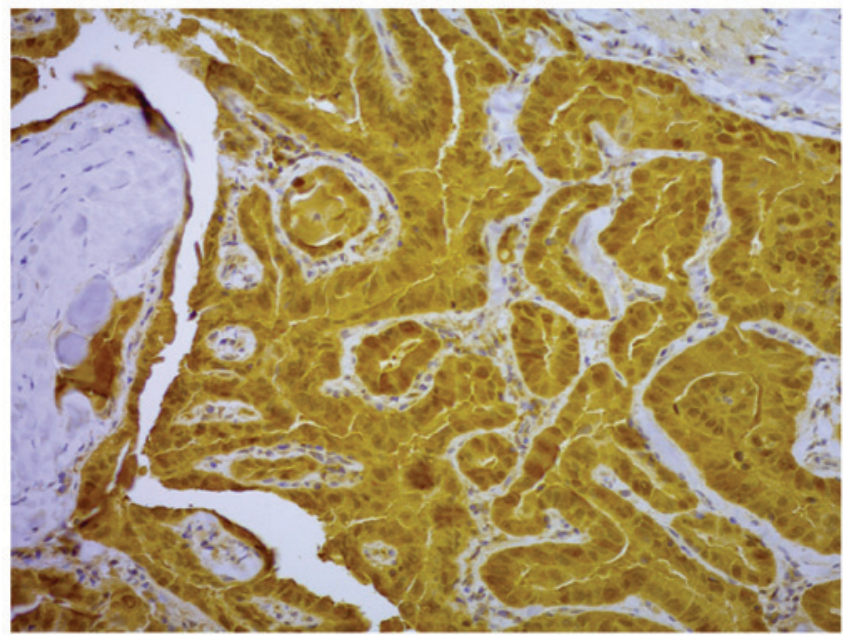

Figure 1. Immunohistochemical stain of the expression of non-metastatic expressed/non-metastatic 23 nucleoside diphosphate kinase 1 in the cytoplasm of papillary carcinoma cells classified as ‘strong'. Magnification, x200.

with distinct tumour characteristics have yet to be been elucidated (24-33). Russell et al (39) demonstrated that cells containing the oncogenic fusion protein RET/protein phosphatase 2C homolog 3 (PTC3) have increased nuclear $\mathrm{NF}-\kappa \mathrm{B}$ activity, which promotes the secretion of myeloid growth and chemotactic factors. RET/PTC3 thyrocytes are able to promote the production of inflammatory mediators, including COX-2 (40).

The nm23-H1 kinase is established as a tumour suppressor gene (6) and has been indicated to have a tumour-suppressing function in a number of types of malignant tumour; however the results of previous studies evaluating the role of $\mathrm{nm} 23-\mathrm{H} 1$ in thyroid cancer are contradictory and remain unclear (7-17).

A direct association between $\mathrm{nm} 23-\mathrm{H} 1$ and $\mathrm{COX}-2$ has been identified in EBV-infected lymphoblastoid cells (34). It was identified that COX-2 transcription may be promoted by $\mathrm{nm} 23-\mathrm{H} 1$ via the NF- $\mathrm{KB}$ signalling pathway (34). The proteins

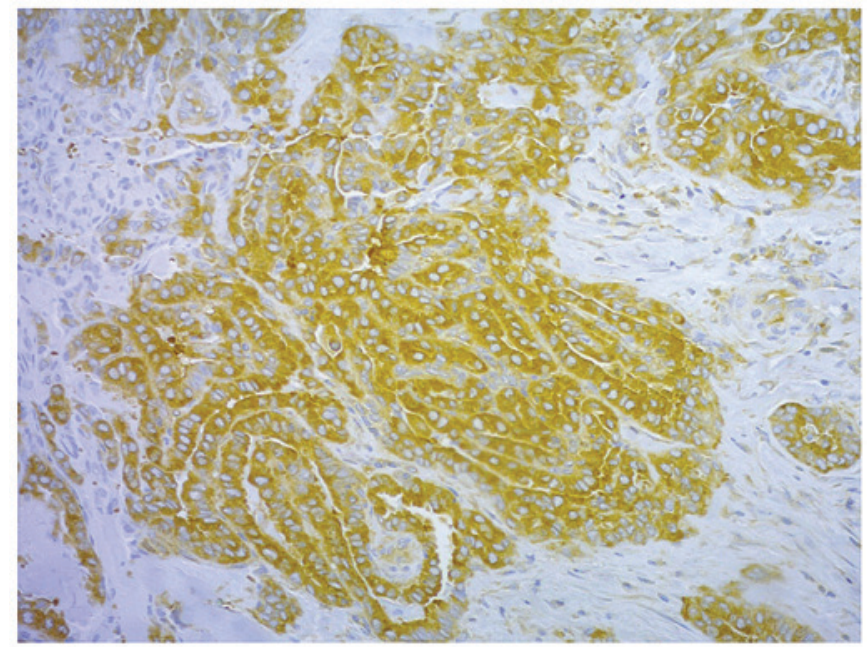

Figure 2. Immunohistochemical stain of the expression of cyclooxygenase 2 in cytoplasm of papillary carcinoma cells classified as 'strong'. Magnification, $\mathrm{x} 200$.

nm23-H1 and COX-2 have each been investigated separately in a number of previous studies, which included $<110$ PTC specimens. To the best of our knowledge, the present study is the first investigation of the coexpression levels of nm23-H1 and COX-2 in PTC tumours. Immunohistochemistry was used to analyse the levels of $\mathrm{nm} 23-\mathrm{H} 1$ and $\mathrm{COX}-2$ protein expression in 130 PTC samples. Increased expression levels of nm23-H1 were identified in $90 \%$ of the tumour tissues $(118 / 130)$. The proportion of tumours with increased expression levels of COX-2 was lower at $67.6 \%$ (88/130) and 87 of the tumour samples also exhibited an increased level of expression of nm23-H1 $(\mathrm{P}<0.001)$. Although these results are not able to elucidate the underlying mechanisms of this observation, these data are concordant with previous results from EBV-infected cells (34).

There was no statistically significant difference between the expression levels of $\mathrm{nm} 23-\mathrm{H} 1$ and $\mathrm{COX}-2$ according to the age or the gender of the patients. Siironen et al (27) used immunohistochemistry to analyse COX-2 protein expression levels in 108 samples from patients with PTC, of which 49 were $>45$ years. The results revealed an increase in the expression levels of COX-2 in this group of patients, compared with the group of patients that were $<45$ $(\mathrm{P}=0.002)$ (27). Due to the results of this previous study, the current study used two groups: Patients who were $<45$ and patients who were $>45$ years at the time of surgery. However the present study did not identify a statistically significant difference in the expression levels of nm23-H1 and COX-2 between these two age groups. Erdem et al (40) analysed the expression levels of COX-2 in 79 PTC tissues using immunohistochemistry and demonstrated increased COX-2 staining in the group of patients who were $>55$ years old $(\mathrm{P}=0.05)$. In this previous study, patients were divided into three age groups as follows: <35 years; 35-55 years; >55 years (40). García-González et al (41) analysed COX-2 expression levels in normal, hyperplastic and neoplastic follicular cells of the thyroid gland from 174 patients using immunohistochemistry. The results did not detect an association between COX-2 expression levels and the patient age or the presence 
Table III. nm23-H1, COX-2 and histological subtype.

\begin{tabular}{|c|c|c|c|c|c|c|c|c|}
\hline & \multirow{2}{*}{$\begin{array}{l}\text { Histological } \\
\text { subtype }\end{array}$} & \multirow[b]{2}{*}{$\mathrm{n}$} & \multirow[b]{2}{*}{ Min. } & \multirow[b]{2}{*}{ Max. } & \multicolumn{3}{|c|}{ Median } & \multirow[b]{2}{*}{ P-value } \\
\hline & & & & & 25 th & 50 th & 75 th & \\
\hline \multirow[t]{4}{*}{$\mathrm{nm} 23-\mathrm{H} 1$} & Follicular & 32 & 1 & 3 & 2 & 3 & 3 & 0.038 \\
\hline & Classical & 67 & 0 & 3 & 2 & 3 & 3 & \\
\hline & Oxyphilic & 10 & 1 & 3 & 2 & 2 & 3 & \\
\hline & Sclerosing & 13 & 0 & 3 & 1.5 & 2 & 3 & \\
\hline \multirow[t]{4}{*}{ COX-2 } & Follicular & 32 & 0 & 3 & 2 & 3 & 3 & 0.006 \\
\hline & Classical & 67 & 0 & 3 & 1 & 2 & 2 & \\
\hline & Oxyphilic & 10 & 1 & 3 & 1 & 2 & 3 & \\
\hline & Sclerosing & 13 & 0 & 3 & 1 & 1 & 2 & \\
\hline
\end{tabular}

Kruskal-Wallis test was used to determine statistical significance. nm23-H1, non-metastatic expressed/non-metastatic 23 nucleoside diphosphate kinase 1; COX-2, cyclooxygenase 2; n, number of samples; min., minimum score; max., maximum score; 25th, 25th percentile score; 50th, 50th percentile score; 75th, 75th percentile score.

Table IV. Lymphocytic inflammatory infiltrate in tumour and thyroiditis in surrounding thyroid tissue.

\begin{tabular}{lcccr}
\hline & \multicolumn{3}{c}{$\begin{array}{c}\text { Lymphocytic } \\
\text { infiltration }\end{array}$} \\
\cline { 3 - 4 } & & Absent & Present & Total \\
\hline Thyroiditis & & & & \\
Absent & $\mathrm{n}$ & 76 & 21 & 97 \\
& $\%$ & 78.4 & 21.6 & 100 \\
Present & $\mathrm{n}$ & 15 & 18 & 33 \\
& $\%$ & 45.5 & 54.5 & 100 \\
Total & $\mathrm{n}$ & 91 & 39 & 130 \\
& $\%$ & 70 & 30 & 100 \\
& $\%$ & & &
\end{tabular}

$\chi^{2}$ test $=12.688$, degrees of freedom $=1 ; \mathrm{P}<0.001 . \mathrm{n}$, number of samples .

of lymph node metastases in 39 patients with PTC (41). Notably, it was identified that there was a significant increase in the percentage of cases of papillary microcarcinoma that exhibited an upregulation of COX-2 compared with all the other types of PTC (41). Kim et al (30) analysed the COX-2 immunohistochemical expression levels in 223 thyroid cancer samples, and they compared the expression levels of COX-2 from clinical data of 168 cases (57 follicular carcinoma, 94 PTC and 17 anaplastic carcinoma). The PTC group included 14 cases of papillary microcarcinoma (30). There was no significant correlation identified between patient age, gender, presence of distant metastasis and the expression levels of COX-2 (30). A positive expression level of COX-2 was inversely associated with tumour size, with papillary microcarcinoma exhibiting the highest expression levels of COX-2 among the types of thyroid cancer examined in this previous study $(\mathrm{P}=0.048)(30)$. Of the 168 thyroid cancer samples, the tumours with lymph node metastases exhibited reduced COX-2 staining compared with tumours that did not metastasise to the lymph node, but there was no statistically significant difference identified (30).

To investigate the potential association between nm23-H1/COX-2 expression levels and specific types of biological characteristic (primarily the metastatic potential), the current study divided the tumour samples into two groups depending on the tumour size. There was no statistically significant difference in the expression levels of nm23-H1 and COX-2 between the groups $(\mathrm{P}=0.924$ and $\mathrm{P}=0.432)$. The 55 papillary microcarcinoma samples were divided into metastatic and non-metastatic ( $n=9$ and $n=46$, respectively). The current study revealed that the COX-2 expression levels were significantly increased in microcarcinoma tumours that occurred with metastases $(\mathrm{P}=0.017)$, compared with those that occurred without metastases. This result is concordant with the hypothesis of a potential role for COX-2 in the aggressive characteristics of papillary microcarcinoma. A previous study indicated that the increased expression levels of COX-2 and reduced expression levels of KAI-1/cluster of differentiation 68 in primary cultures, tumour cell lines and tumour samples of PTC are associated with an increase in the invasiveness of tumours (31).

In the present study, the median expression levels of $\mathrm{nm} 23-\mathrm{H} 1$ were significantly increased in the classical and follicular histological subtypes of papillary carcinoma compared with all other histological subtypes $(\mathrm{P}=0.038)$. The median expression levels of COX-2 were significantly increased in the follicular histological subtype, but were significantly decreased in the diffuse-sclerosing subtype of PTC tumour $(\mathrm{P}=0.006)$. The presence of lung metastases at the time of diagnosis is typical of the diffuse-sclerosing subtype of PTC and this may be associated with the tumour possessing aggressive characteristics (1). In the present study, 13 of the cases were of this histological subtype and there were no lung metastases present in the patients at the time of diagnosis. Therefore, these results are not able to elucidate the role of COX-2 expression and the pathogenicity of this subtype of PTC.

The association between chronic inflammation and carcinogenesis via activation of COX-2 has been established 


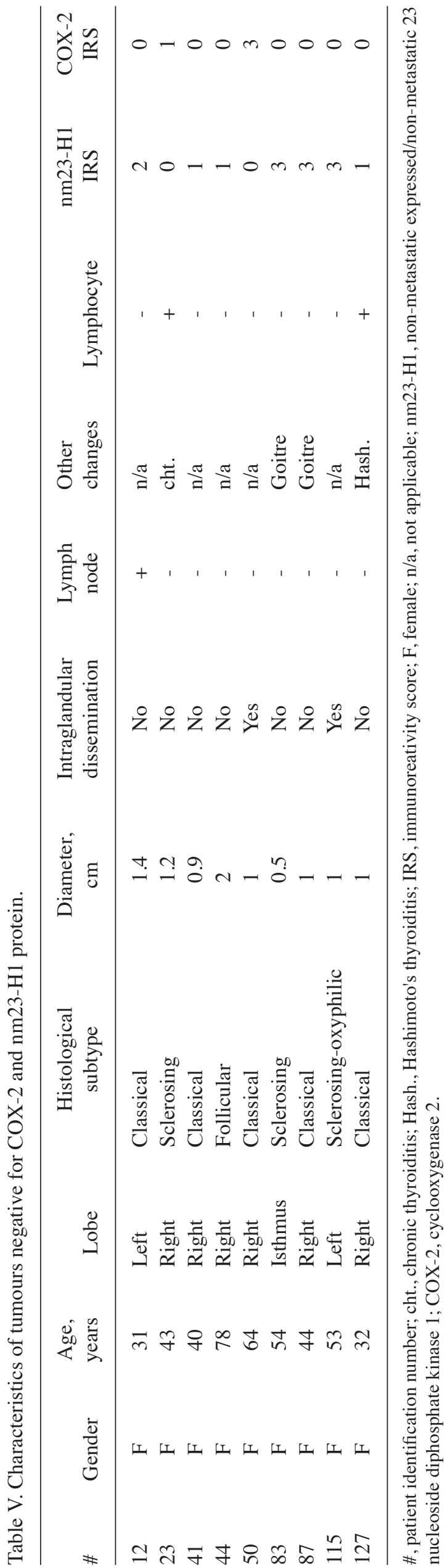

Table VI. Expression of nm23-H1 in papillary microcarcinoma with or without lymph node metastasis.

\begin{tabular}{lcccc}
\hline & & \multicolumn{2}{c}{$\mathrm{nm} 23-\mathrm{H} 1$} & score \\
\cline { 3 - 4 } & & 0,1 & 2,3 & Total \\
\cline { 3 - 4 } Lymph node metastasis & & & & \\
Absent & $\mathrm{n}$ & 5 & 41 & 46 \\
& $\%$ & 10.9 & 89.1 & 100 \\
Present & $\mathrm{n}$ & 0 & 9 & 9 \\
\multirow{2}{*}{ Total } & $\%$ & 0 & 100 & 100 \\
& $\mathrm{n}$ & 5 & 50 & 55 \\
& $\%$ & 9.1 & 90.9 & 100 \\
\hline
\end{tabular}

$\chi^{2}$ test $=1.076$, degrees of freedom $=1 ; \mathrm{P}=0.300 . \mathrm{n}$, number of samples; nm23-H1, non-metastatic expressed/non-metastatic 23 nucleoside diphosphate kinase 1.

Table VII. Expression of COX-2 in papillary microcarcinoma with or without lymph node metastasis.

\begin{tabular}{lcccc}
\hline & & \multicolumn{2}{c}{ COX-2 score } & \\
\cline { 3 - 4 } & & 0,1 & 2,3 & Total \\
\hline Lymph node metastasis & & & & \\
Absent & $\mathrm{n}$ & 19 & 27 & 46 \\
& $\%$ & 41.3 & 58.7 & 100 \\
Present & $\mathrm{n}$ & 0 & 9 & 9 \\
\multirow{2}{*}{ Total } & $\%$ & 0 & 100 & 100 \\
& $\mathrm{n}$ & 19 & 36 & 55 \\
& $\%$ & 34.5 & 65.5 & 100
\end{tabular}

$\chi^{2}$ test $=5.679$, degrees of freedom $=1 ; \mathrm{P}=0.017 . \mathrm{n}$, number of samples; COX-2, cyclooxygenase 2 .

previously (42). In the present study, the presence of lymphocyte inflammatory infiltrate in the tumour was associated with the presence of thyroiditis in the tissues surrounding the tumour $(\mathrm{P}<0.001)$, but it was not associated with the expression levels of nm23-H1 and COX-2 in the tumour tissue.

The results presented in the current study demonstrate that the presence of COX-2 may be an important diagnostic marker of thyroid papillary microcarcinoma, as its expression levels demonstrated an association with lymph node metastasis. The results also indicated that coexpression of COX-2 and $\mathrm{nm} 23-\mathrm{H} 1$ may be associated, with this coexpression being associated with a distinct histological subtype of PTC. Although the underlying mechanisms of the role of COX-2 and $\mathrm{nm} 23-\mathrm{H} 1$ in thyroid carcinogenesis have yet to be elucidated, the results presented in the current study may inform further investigations into the origin and progression of thyroid papillary carcinoma and microcarcinoma.

In conclusion, the current study demonstrates that coexpression of nm23-H1 and COX-2 is typical of papillary thyroid 
carcinoma. However, the levels of their expression may not be associated with commonly examined clinical parameters, including age, gender and the metastatic potential of the tumour. However, the results identified a statistically significant increase in the median expression levels of nm23-H1 in the classical and follicular subtypes of PTC tissues compared with other tumours subtypes. The median expression levels of COX-2 were also significantly increased in follicular subtypes and decreased in diffuse-sclerosing subtypes. Although the latter result demonstrated statistical significance, there were only 13 tumours of this histological subtype and therefore this trend requires further study.

\section{References}

1. DeLellis RA, Lloyd RV, Heitz PU and Eng C (eds): Papillary carcinoma. In: World health organization classifications of tumours: Pathology and genetics of tumours of endocrine organs. IARC Press, Lyon, pp57-66, 2004.

2. Toniato A, Boshin I, Casara D, Mazzarotto R, Rubello D and Pelizzo M: Papillary thyroid carcinoma: Factors influencing recurrence and survival. Ann Surg Oncol 15: 1518-1522, 2008.

3. Spriano G, Ruscito P, Pellini R, Appetecchia M and Roselli R: Pattern of regional metastases and prognostic factors in differentiated thyroid carcinoma. Acta Otorhinolaryngol Ital 29: 312-316, 2009.

4. Ito $\mathrm{Y}$ and Miyauchi A: Prognostic factors and therapeutic strategies for differentiated carcinoma of the thyroid. Endocr J 56: 177-192, 2009

5. Jung TS, Kim TY, Kim KW, Oh YL, Park DJ, Cho BY, Shong YK, Kim WB, Park YJ, Jung JH and Chung JH: Clinical features and prognostic factors for survival in patients with poorly differentiated thyroid carcinoma and comparison to the patients with the aggressive variants of papillary thyroid carcinoma. Endocr J 54 265-274, 2007

6. Yoshida BA, Skoloff MM, Welch DR and Rinker-Schaeffer CW: Metastasis-supressor genes: A review and perspective on an emerging field. J Natl Cancer Inst 92: 1717-1730, 2000.

7. Rosengard AM, Krutzsch HC, Shearn A, Biggs JR, Barker E, Marguilies IM, King CR, Liotta LA and Steeg PS: Reduced $\mathrm{Nm} 23 /$ Awd protein in tumour metastasis and aberrant Drosphila development. Nature 342: 177-180, 1989.

8. Lacombe ML, Milon L, Munier A, Mehus JG and Lambeth DO: The human Nm23/nucleoside diphosphate kinases. J Bioenerg Biomembr 32: 247-258, 2000.

9. Ouatas T, Salerno M, Palmieri D and Steeg PS: Basic and translational advances in cancer metastasis: Nm23. J Bioenerg Biomembr 35: 73-79, 2003.

10. Lee JH, Marshall JC, Steeg PS and Horak CE: Altered gene and protein expression by $\mathrm{Nm} 23-\mathrm{H} 1$ in metastasis suppression. Mol Cell Biochem 329: 141-148, 2009.

11. Zou M, Shi Y, Al-Sedairy S and Farid NR: High levels of Nm23 gene expression in advanced stage of thyroid carcinomas. Br J Cancer 68: 385-388, 1993.

12. Ferenc T, Lewiński A, Lange D, Niewiadomska H, Sygut J, Sporny S, Włoch J, Sałacińska-Los E, Kulig A and Jarzab B: Analysis of Nm23-H1 protein immunoreactivity in follicular thyroid tumors. Pol J Pathol 55: 149-153, 2004.

13. Luo W, Matsuo K, Nagayama Y, Urano T, Furukawa K, Takeshita A, Nakayama T, Yokoyama N, Yamashita S and Izumi M: Immunohistochemical analysis of expression of $\mathrm{nm} 23-\mathrm{H} 1 /$ nucleoside diphosphate kinase in human thyroid carcinomas: Lack of correlation between its expression and lymph node metastasis. Thyroid 3: 105-109, 1993.

14. Farley DR, Eberhardt NL, Grant CS, Schaid DJ, van Heerden JA, Hay ID and Khosla S: Expression of a potential metastasis suppressor gene (nm23) in thyroid neoplasms. World J Surg 17: 615-621, 1993

15. Royds JA, Silcocks PB, Rees RC and Stephenson TJ: Nm23 protein expression in thyroid neoplasms. Pathologica 86 240-243, 1994.

16. Tabriz HM, Adabi Kh, Lashkari A, Heshmat R, Haghpanah V, Larijani B and Tavangar SM: Immunohistochemical analysis of $n \mathrm{~m} 23$ protein expression in thyroid papillary carcinoma and follicular neoplasm. Pathol Res Pract 205: 83-87, 2009.
17. Shahebrahimi K, Madani SH, Fazaeli AR, Khazaei S, Kanani M and Keshavarz A: Diagnostic value of CD56 and nm23 markers in papillary thyroid carcinoma. Indian J Pathol Microbiol 56: 2-5, 2013.

18. Maud JF, Alfin-Slater RB, Howton DR and Popjak G: Prostaglandins, tromboxanes and prostacyclin. In: Lipids: Chemistry, Biochemistry, and Nutrition. Springer US, New York, NY, pp149-216, 1986.

19. Crofford LJ: COX-1 and COX-2 tissue expression: Implications and predictions. J Rheumatol Suppl 49: 15-19, 1997.

20. NCBI Gene: PTGS1 prostaglandin-endoperoxide synthase 1 [Homo sapiens (human)]. GENE ID: 5742, updated on 20-Feb-2017. www.ncbi.nlm.nih.gov/gene/5742.

21. NCBI Gene: PTGS2 prostaglandin-endoperoxide synthase 2 [Homo sapiens (human)]. GENE ID: 5743, updated on 26-Feb-2017. www.ncbi.nlm.nih.gov/gene/5743.

22. Dubois RN, Abramson SB, Crofford L, Gupta RA, Simon LS, van de Putte LB and Lipsky PE: Cyclooxygenase in biology and disease. FASEB J 12: 1063-1073, 1998.

23. Vane JR, Bakhle YS and Botting RM: Cyclooxigenases 1 and 2. Annu Rev Pharmacol Toxicol 38: 97-120, 1998.

24. Specht MC, Tucker ON, Hocever M, Gonzalez D, Teng L and Fahey TJ III: Cyclooxygenase-2 expression in thyroid nodules. J Clin Endocronol Metab 87: 358-363, 2002.

25. Ji B, Liu Y, Zhang P, Wang Y and Wang G: COX-2 expression and tumor angiogenesis in thyroid carcinoma patients among northeast Chinese population-result of a single-center study. Int J Med Sci 9: 237-242, 2012

26. Krawczyk-Rusiecka K, Wojciechowska-Durczynska K, Cyniak-Magierska A, Zygmunt A and Lewinski A: Assessment of cyclooxygenase- 1 and 2 gene expression levels in chronic autoimmune thyroiditis, papillary thyroid carcinoma and nontoxic nodular goitre. Thyroid Res 7: 10, 2014.

27. Siironen P, Ristimäki A, Nordling S, Louhimo J, Haapiainen R and Haglund C: Expression of Cox-2 is increased with age in papilary thyroid cancer. Histopathology 44: 490-497, 2004.

28. Kim SJ, Lee J, Yoon JS, Mok JO, Kim YJ, Park HK, Kim CH, Byun DW, Suh KI and Yoo MH: Immunohistochemical expression of COX-2 in thyroid nodules. Korean J Int Med 18: 225-229, 2003.

29. Ito Y, Yoshida H, Naakano K, Takamura Y, Miya A, Kobayashi K, Yokozawa T, Matsuzuka F, Matsuura N, Kuma K and Miyauchi A: Cyclooxygenase-2 expression in thyroid neoplasms. Histopathology 42: 492-497, 2003.

30. Kim YA, Chang M, Park YJ and Kim JE: Detection of survivin and COX-2 in thyroid carcinoma: Anaplastic carcinoma shows overexpression of nuclear surviving and low COX-2 expression. Korean J Pathol 46: 55-60, 2012.

31. Scarpino S, Duranti E, Giglio S, Di Napoli A, Galafate D, Del Bufalo D, Desideri M, Socciarelli F, Stoppacciaro A and Ruco L: Papillary carcinoma of the thyroid: High expression of COX-2 and low expression of KAI-1/CD82 are associated with increased tumor invasiveness. Thyroid 23: 1127-1137, 2013.

32. Cornetta AJ, Russell JP, Cunnane M, Keane WM and Rothstein JL: Cyclooxygenase-2 expression in human thyroid carcinoma and Hashimoto's thyroiditis. Laryngoscope 11: 238-242, 2002.

33. Nose F, Ichikawa T, Fujiwara M and Okayasu I: Up-regulation of cyclooxygenase-2 expression in lymphocytic thyroiditis and thyroid tumors: Significant correlation with inducible nitric oxide synthase. Am J Clin Pathol 117: 546-551, 2002.

34. Kaul R, Verma SC, Murakami M, Lan K, Choudhuri T and Robertson ES: Epstein-Barr virus protein can upregulate cyclo-oxygenase-2 expression through association with the supressor of metastasis Nm23-H1. J Virol 80: 1321-1331, 2006.

35. Joo YE, Kim HS, Min SW, Lee WS, Park CH, Park CS, Choi SK, Rew JS and Kim SJ: Expression of cyclooxigenase-2 protein in colorectal carcinomas. Int J Gastrointest Cancer 31: 147-154, 2002.

36. Soslow RA, Dannenberg AJ, Rush D, Woerner BM, Khan KN, Masferrer J and Koki AT: COX-2 is expressed in human pulmonary, colonic, and mammary tumors. Cancer 89: 2637-2645, 2000.

37. Barnes R, Masood S, Barker E, Rosengard AM, Coggin DL, Crowell T, King CR, Porter-Jordan K, Wargotz ES and Liotta LA: Low $\mathrm{nm} 23$ protein expression in infiltrating ductal breast carcinomas correlates with reduced patient survival. Am J Pathol 139: 245-250, 1991.

38. Yamaguchi A, Ding K, Maehara M, Goi T and Nakagawara G: Expression of nm23-H1 gene and Sialyl Lewis $\mathrm{x}$ antigen in breast cancer. Oncology 55: 357-362, 1998 
39. Russell JP, Shinohara S, Melillo RM, Castellone MD, Santoro M and Rothstein JL: Tyrosine kinase oncoprotein, RET/PTC3, induces the secretion of myeloid growth and chemotactic factors. Oncogene 22: 4569-4577, 2003.

40. Erdem H, Gündogdu C and Şipal S: Correlation of E-cadherin, VEGF, COX-2 expression to prognostic parameters in papillary thyroid carcinoma. Exp Mol Pathol 90: 312-317, 2011.

41. García-González M, Abdulkader I, Boquete AV, Neo XM, Forteza $\mathrm{J}$ and Cameselle-Teijeiro J: Cyclooxigenase-2 in normal, hyperplastic and neoplastic follicular cells of the human thyroid gland. Virchows Arch 447: 12-17, 2005.
42. Eschwège $P$, de Ledinghen V, Camilli T, Kulkarni S, Dalbagni G, Droupy S, Jardin A, Benoît G and Weksler BB: Arachidonic acid and prostaglandins, inflammation and oncology. Presse Med 30: 508-510, 2001 (In French). 